\title{
Colorectal endoscopic submucosal dissection using a clip-on-clip traction method
}

To safely and efficiently perform colorectal endoscopic submucosal dissection (ESD), clear visualization of the submucosal layer is important. Therefore, various traction methods have been developed to date [1 - 3]. However, there are few reports of using special devices other than clips, and traction methods that are generally used have not been reported. Recently, we developed a new clip-on-clip closure method to close the mucosal defect after ESD using clips only [4]. Here, we describe a new traction method: clipon-clip traction method (CCTM).

The colorectal ESD method using CCTM is shown in $>$ Video 1 . The patient had a nongranular laterally spreading tumor, $20 \mathrm{~mm}$ in size, in the rectosigmoid. Marking was done around the lesion and a fullcircumference incision was made. First, a clip was placed on the mucous membrane on the lesion side ( $\mathbf{F i g} \mathbf{1} \mathbf{a}$ ). Then, a second clip was placed on the handle of the first clip ( $\mathbf{F i g . 1} \mathbf{b}$ ). Next, the teeth of a third clip were passed through the gap between the teeth of the second clip, which served as an anchor, and then fixed to the contralateral normal colorectal mucosa ( $>$ Fig. 1 c). In the current case, the third clip did not fix to the contralateral colorectal mucosa. However, there was adequate space between the teeth of the second clip for

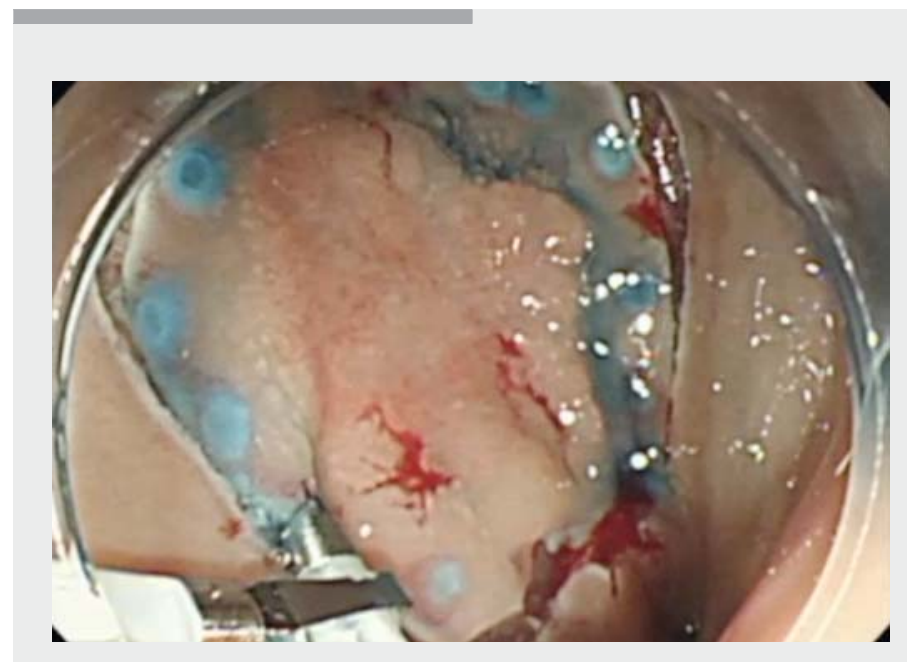

Video 1 Colorectal endoscopic submucosal dissection and troubleshooting using the clip-on-clip traction method.

a fourth clip to be added. This ensured a strong traction.

Because the submucosa could be viewed properly using CCTM, colorectal ESD could be performed safely without any intraoperative adverse event. As the resected lesion was fixed with a clip to the contralateral side, the lesion could be removed from the mucosa with a grasping forceps.

CCTM is simple, and is a novel method that can be applied safely to achieve effective traction even in a narrow intestinal tract, such as the rectosigmoid or sigmoid colon.

Endoscopy_UCTN_Code_TTT_1AQ_2AD

\section{Competing interests}

None
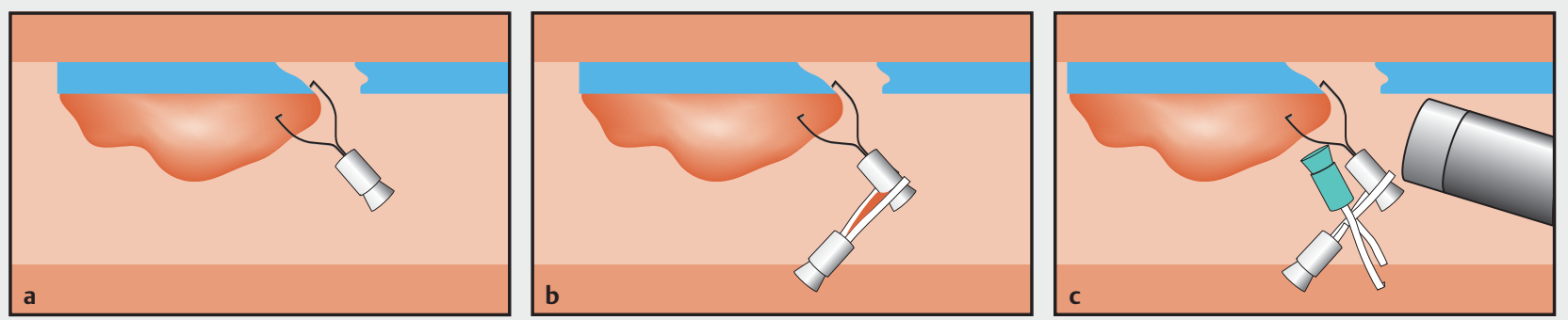

Fig. 1 Colorectal endoscopic submucosal dissection schema using the clip-on-clip traction method. a After full-circumference incision of the lesion, the first clip was placed on the mucous membrane on the lesion side. $\mathbf{b}$ A second clip was placed on the handle of the first clip. The gap between the teeth of the second clip (red area) was used as an anchor. c The teeth of a third clip (green) were passed through the gap, and then fixed to the contralateral normal mucosa. 
The authors

Tatsuma Nomura ${ }^{1,2}$, Akira Kamei ${ }^{2}$, Shinya Sugimoto ${ }^{2}$, Jun Oyamada ${ }^{2}$

1 Department of Gastroenterology, Kinan Hospital, Minamimuro, Japan

2 Department of Gastroenterology, Ise Red Cross Hospital, Ise, Japan

Corresponding author

Tatsuma Nomura, MD

Department of Gastroenterology, Kinan Hospital, 4750 Atawa, Mihama-cho, Minamimuro-gun, Mie 519-5293, Japan Fax: +815-9792-3357

m06076tn@icloud.com

\section{References}

[1] Osada T, Sakamoto N, Shibuya T et al. "Loops-attached rubber band" facilitation of endoscopic submucosal dissection of superficial colorectal neoplasm. Endoscopy 2008; 40 (Suppl. 02): E101-E102

[2] Matsuzaki I, Isobe S, Hirose K et al. Magnetic anchor-guided endoscopic submucosal dissection for colonic tumor. VideoGIE 2017; 2: $74-75$

[3] Nomura T, Kamei A, Sugimoto $S$ et al. Colorectal endoscopic submucosal dissection using the "dental floss with rubber band method". Endoscopy 2018; 50: E78 - E80

[4] Nomura T, Kamei A, Sugimoto $S$ et al. New closure method for a mucosal defect after endoscopic submucosal dissection: the clipon-clip closure method. Endoscopy 2018. doi:10.1055/s-0044-100486

\section{Bibliography}

DOI https://doi.org/10.1055/a-0605-2868

Published online: 7.6.2018

Endoscopy 2018; 50: E197-E198

(c) Georg Thieme Verlag KG

Stuttgart · New York

ISSN 0013-726X

\section{ENDOSCOPY E-VIDEOS \\ https://eref.thieme.de/e-videos} 回回 Endoscopy E-Videos is a free access online section, reporting 口f: on interesting cases and new techniques in gastroenterological endoscopy. All papers include a high quality video and all contributions are freely accessible online.

This section has its own submission website at https://mc.manuscriptcentral.com/e-videos 